\title{
Effect of Growth Regulators Concentrations on in Vitro Multiplication of Three Elite Sugarcane (Saccharum Officinarum L.) Genotypes using Shoottip Culture
}

Gerema Amente ( $\square$ amente2015@gmail.com )

Oromia Agricultural Research Institute Adami Tulu Agricultural Research Center

Tileye Feyissa

Institute of Biotechnology , Addis Ababa University

\section{Research Article}

Keywords: Genotypes, 6-Benzylaminopurine, Kinetin, Invitro Micro propagation

Posted Date: July 1st, 2021

DOI: https://doi.org/10.21203/rs.3.rs-648670/v1

License: (c) (i) This work is licensed under a Creative Commons Attribution 4.0 International License.

Read Full License 


\title{
Effect of Growth Regulators Concentrations on in vitro Multiplication of three Elite Sugarcane (Saccharum officinarum L.) genotypes using Shoot tip Culture
}

\author{
Gerema Amente ${ }^{1}$, Dr.Tileye Feyissa ${ }^{2}$ \\ ${ }^{1}$ Senior Researcher, Adami Tulu Agricultural Research Center \\ Oromia Agricultural Research Institute, \\ Batu, Oromia, Ethiopia \\ Email address: amente2015@gmail.com \\ Mobile no.: +251921184100/+251947496961 \\ ${ }^{2}$ Assistant Professor, Institute of Biotechnology, \\ Addis Ababa University, Addis Ababa, Ethiopia \\ Email address: tileye feyissa@yahoo.com \\ Mobile no.:+251911949025
}

\begin{abstract}
Conventional vegetative propagation of sugarcane generally has low multiplication rate and allows distribution of diseases. Micropropagation is the only practical means of achieving rapid, large-scale production of disease-free quality planting material. Experiments on shoot tip culture initiation and shoot multiplication were laid out in completely randomized design with $2 \times 3 \times 3$ and $4 \times 5 \times 3$ factorial treatment arrangements respectively. Data was subjected to analysis of variance (ANOVA) and significant means were separated using Duncan's multiple range tests. With regard to shoot multiplication, genotype Q200 showed a maximum of 13.59 shoots per explant with $5.83 \mathrm{~cm}$ shoot length on a medium fortified with $2 \mathrm{mg} / \mathrm{l} B A P$ alone, while genotype Q217 produced a maximum of 15.28 shoots per explant with $5.37 \mathrm{~cm}$ mean shoot length on a medium supplied with $2.0 \mathrm{mg} / \mathrm{l}$ BAP and $0.25 \mathrm{mg} / \mathrm{l}$ kinetin. Likewise, Co-0238 produced maximum of 13.56 shoots per explant with mean shoot length $6.50 \mathrm{~cm}$ on medium fortified with $1.5 \mathrm{mg} / \mathrm{l} B A P+0.5 \mathrm{mg} / \mathrm{l}$ kinetin
\end{abstract}

Key-words: Genotypes, 6-Benzylaminopurine, Kinetin, Invitro Micro propagation

\section{*Corresponding author E-Mail: amente2015@gmail.com (Mr. Gerema A)}

\section{Introduction:}

The sugar industry has great contributions to the socio-economy of the country, given its agricultural and industrial investments, foreign exchange earnings, its high employment, and its linkages with major suppliers, support industries and customers (Belay et al., 2014). Hence, much research has been focused on sugarcane crop improvement through conventional breeding and quite recently, extensive attention has been paid to biotechnological approaches (Baksha et al., 2003; Hoy et al., 2003).

Conventional propagation of sugarcane in general suffered from low propagation rates, expensive labor, large land areas demand, time consuming and potential transmission of pathogens from the seed cane to the subsequent crop limits the efficiency of this method (Sandeep et al., 2009). Much research has been focused on sugarcane crop improvement through conventional breeding and quite recently, extensive attention has been paid to biotechnological approaches (Baksha et al., 2003; Hoy et al., 2003). Therefore, efficient propagation system is required for mass multiplication of sugarcane in a short period of time. 
Rapid clonal propagation of sugarcane planting materials depends on the genotype and the plant growth regulators combinations used and needs to develop plant growth regulators combinations for each genotype (Singh et al., 2006, Melaku et al., 2016). Plant growth regulators necessities for in vitro propagation responses differ from cultivar to cultivar in sugarcane (Pathak et al., 2009). It is necessary that an efficient protocol is needed for every new variety or clone of sugarcane to get rapid shoot initiation and shoot multiplication. Thus, this research work was designed with the objective to study effect of growth regulators concentrations on in vitro multiplication of sugarcane genotypes (Q200, Q217 and Co-0238) using shoot tip explants

\section{Materials and methods}

The study was conducted at Holeta National Agricultural Biotechnology Laboratory of the Ethiopian Institute of Agricultural Research. Three elite sugarcane genotypes (Q-200, Q-217 and Co-0238) were used for the study. They were obtained from the Ethiopian Sugar Corporation, Research and Training Division. The Sugar Corporation imported Q200 and Q-217varieties from Australia and Co- 0238 variety from India. These genotypes are among the selected ones to be commercialized by the Ethiopian Sugar Corporation for their cane yield performance and sugar quality.

\subsection{Culture Media Preparation and Sterilization}

The basal medium employed for the culture is MS medium (Murashige and Skoog, 1962). The required amount of macronutrient, micronutrient, vitamins from their respective stock solution were dissolved in double distilled water along with $30 \mathrm{~g} / \mathrm{L}$ sucrose (for initiation and multiplication)

The final volume was made up to the required level with double distilled water and then divided into required volume of treatments, to which amount of PGRs from stock solution were added in combinations at different concentrations. The $\mathrm{pH}$ was adjusted in all cases to 5.8 by using $1 \mathrm{~N} \mathrm{NaOH}$ and/or $1 \mathrm{~N}$ HCL before gelling with agar. Agar-Agar type I (4.5 g/l for culture initiation) and Phytagel ( $2.0 \mathrm{~g} / 1$ for multiplication) were added to the nutrient and heated on magnetic hot plate till it was completely melted. Before autoclaving, the media was poured into washed and dried test tubes of $30 \mathrm{ml}$ volume for initiation and $50 \mathrm{ml}$ volume of culture jars for multiplication, then, capped and labeled properly. The dispensed medium was then autoclaved at $121^{\circ} \mathrm{C}$ for 15 minutes at 15 -psi pressure.

\subsection{Explant collection and sterilization}

The intact leaves were removed, and the segments with leave sheath were taken to the laboratory for surface sterilization and explant preparation. Trimmed shoot tips were washed thoroughly under running tap water for 20 minutes, and resized to just about 10 $\mathrm{cm}$ length by cutting off at the two ends. Then the explants were further washed for 30 minutes with tap water containing a drop of liquid detergent (Largo liquid soap) solution 
plus two drops of tween-20 with continuous shaking and rinsed three times with double distilled water. Later, the explant was taken to a laminar air flow cabinet and immersed in $0.3 \%(\mathrm{w} / \mathrm{v})$ Kocide fungicide solution, ascorbic acid $(0.2 \% \mathrm{w} / \mathrm{v})$ and citric acid $(0.4 \% \mathrm{w} / \mathrm{v})$ for 30 minutes followed by three times rinsing each for five minutes with autoclaved double distilled water(Belay $\mathrm{T}$, et al 2014).

The shoot tips were washed again with $70 \%$ ethanol for one minute and 30 seconds and rinsed with sterile double distilled water three times each for five minute to remove residual ethanol from the shoot tip surface. Finally, $2.5 \mathrm{~cm}$ sized explants were surface sterilized with $50 \%(\mathrm{v} / \mathrm{v})$ aqueous solution of Sodium hypochlorite bleach $(5 \% \mathrm{v} / \mathrm{v}$ active chlorine) containing two drops of a wetting agent (tween-20) with gentle shaking for 25 minutes. After pouring out sodium hypochlorite solution, the explants were rinsed with sterile double distilled water three times for five minutes to remove all traces of the sterilant. All the steps of sterilization were carried out under aseptic condition

\subsection{Shoot initiation from shoot tip explant}

Shoot tip containing apical meristem of genotypes Q-200, Q-217 and Co-0238 were cultured on MS medium containing different concentrations and combinations of BAP $(0.0,1.5$ and $2.0 \mathrm{mg} / \mathrm{l})$ and IBA $(0.0$ and $0.5 \mathrm{mg} / \mathrm{l}), 30 \mathrm{~g} / 1$ sucrose and $4.5 \mathrm{~g} / 1$ agar. The factorial treatment was $3 \times 2 \times 3$ combinations arrangements. The experiment was carried out at growth room temperature of $25^{\circ} \mathrm{C} \pm 2^{\circ} \mathrm{C}$ under 16 hours photoperiod with light intensity of $30 \mu \mathrm{mol} \mathrm{m}-2 \mathrm{~s}-1$ provided by cool white fluorescent light and $70 \%$ to $80 \%$ relative humidity. Thirty test tubes with each having one shoot tip explant were cultured for each three genotypes (30 shoot tips per treatment). Sub culturing was done frequently (7 days). Data of shoot initiation were recorded three weeks after culture

\subsection{In vitro Shoot Multiplication}

Healthy micro-shoots having same size obtained from the subculture stage were used for shoot multiplication experiment after maintaining on plant growth regulator free semisolid medium for two weeks. These micro-shoots were transferred to full MS semisolid media containing $\operatorname{BAP}(0,0.5,1.0,1.5 \& 2 \mathrm{mg} / \mathrm{l})$ in combination with kinetin $(0,34: 0.25$, $0.5 \& 1.0 \mathrm{mg} / \mathrm{l}$ ) and supplemented with $30 \mathrm{~g} / \mathrm{l}$ sucrose. The experiment was laid out in CRD with three factor factorial combination of five levels of $\operatorname{BAP}(0,0.5,1.0,1.5 \& 2$ $\mathrm{mg} / \mathrm{l})$; four levels of kinetin $(0,0.25,0.5 \& 1.0 \mathrm{mg} / \mathrm{l})$ and three levels of sugarcane genotypes (Q200, Q217 and Co-0238) resulting in 3x5x4 factorial treatment combinations arrangement. Each treatment was replicated three times and four shoot bunches (12 shoot bunches per treatment) were cultured in each culture jar. Sub-culturing was carried out at 15 days interval to obtain shoot multiplication. Data on number of shoots per explants, 
length of shoots and number of leaves per shoot were carefully recorded during each sub culturing.

\subsection{Data Analysis}

The analysis of variance for different variables was performed by GenStat Version 15.1, (GenStat15.1 (64-bit Edition) 2012, VSN International Ltd.) and for significantly different treatments, mean separation was done with Duncan's multiple range tests at or below the probability level of $5 \%$

\subsection{Statement on Plant Guidelines}

This study was performed in accordance with the relevant institutional, national, and international guidelines and legislation.

\section{Results \& Discussion}

\subsection{Culture Initiation}

The shoot tip explants on full MS media lacking of plant growth regulator (control) failed to grow. However, shoot initiation was observed in MS media supplemented with PGR. Healthy and vigorous shoots started appearing within 6-8 days in many of the culture tubes containing $2.0 \mathrm{mg} / \mathrm{L} \mathrm{BAP}$ in combination with $0.5 \mathrm{mg} / \mathrm{L} \mathrm{IBA}$, in Q200 and Q217 varieties, while 8-10 days in Co-0238 variety on medium containing $1.5 \mathrm{mg} / \mathrm{L}$ BAP in combination with $0.5 \mathrm{mg} / \mathrm{L}$ IBA in the culture tubes. The percent establishment varied between different combinational levels of BAP and IBA. Frequency of establishment was maximum for Q217 (86.6\%) and Q200 (90\%) genotypes at $2.0 \mathrm{mg} / \mathrm{L}$ of BAP and $0.5 \mathrm{mg} / \mathrm{L}$ of IBA hormone combination (Table.1 and Figure 1(B) and Figure 1(A)), while it was maximum in case of Co-0238(93.3\%) variety at $1.5 \mathrm{mg} / \mathrm{L}$ of BAP and $0.5 \mathrm{mg} / \mathrm{L}$ of IBA, on which shoots were active and healthy (Table.1 and Figure $1(\mathrm{C})$ ). The study of Tilahun et al. (2014) indicated that normal shoot initiation and establishment was obtained in two cultivars Co449 and Co678 with $2.0 \mathrm{mg} / \mathrm{L}$ of BAP and 0.5mg/L of IBA, which was similar result with Q200 and Q217 variety. Godheja et al. (2014) reported that initiation of shoot tip explant of Co-86032 variety was maximum at $1.0 \mathrm{mg} / \mathrm{L}$ BAP. The study of Sawant and Meti (2016) showed that variety Co86032 shoot formation (96.67\%) on MS medium supplemented with BAP $(0.2 \mathrm{mg} / \mathrm{L})$ and Kinetin $(0.1 \mathrm{mg} / \mathrm{L})$, on the other hand variety CoC671 showed maximum shoot formation (93.33\%) on MS medium supplemented with only Kinetin( $0.5 \mathrm{mg} / \mathrm{L})$. The study of Sandeep et al. (2008) also indicated shoot initiation and establishment was obtained in cultivars of CoC-671 at $2.0 \mathrm{mg} / \mathrm{L}$ of BAP. These observations showed that the concentration of BAP and IBA required for shoot initiation and establishment varies with genotypes. The amount of cytokinin applied depends on the genotype used and the micro propagation strategy employed 


\subsection{Shoot Multiplication}

Analysis of variance revealed that the interaction effects of genotype, BAP and kinetin was very highly significant on the number of shoots per explant, average shoot length $(\mathrm{cm})$ and number of leaves per shoot. The interaction of genotype, BAP and kinetin indicated that all the three factors are reliant on each other for in vitro shoot proliferation of sugarcane. Shoot multiplication was not observed within 4 weeks when shoot explants were cultured on MS medium without plant growth regulators in all the three genotypes. However, increasing the concentration of kinetin alone from $0.0 \mathrm{mg} / \mathrm{L}$ to $0.25 \mathrm{mg} / \mathrm{L}$ resulted in 5.22, 6.51 and 5.39 shoots per explant for Q-200, Q-217 and Co-0238, respectively. In the same way, increasing BAP concentration alone from $0.0 \mathrm{mg} / \mathrm{L}$ to 0.5 $\mathrm{mg} / \mathrm{L}$ gave 5.50, 5.49 and 3.57 shoot per explant in genotype Q-200, Q-217 and Co-0238, respectively. This result indicates that the supplementation of exogenous plant growth regulators to MS medium is fundamental to develop multiple shoots. Certainly, cytokinins are capable of overcoming apical dominance and release lateral buds from dormancy thereby boost shoot multiplication (George et al., 2008).

It was observed that the three genotypes responded differently to the same media for all parameters studied. A significantly highest average number of shoots per explant (13.59), with average shoot length $6.97 \mathrm{~cm}$ and 5.83 number of leaves per shoot was observed in genotype Q200 on MS medium fortified with $2.0 \mathrm{mg} / \mathrm{L}$ BAP alone (Table 2 and Figure 2(A)), while Q217 and Co-0238 gave only 5.16 and 6.43 shoots per explant, respectively on the same medium composition. Among different combinations of BAP and Kin, genotype Q217 produced the highest number of shoots per explant (15.28) with mean shoot length of $6.30 \mathrm{~cm}$ and average number of leaves per shoot of 5.37 on MS medium fortified with $2.0 \mathrm{mg} / \mathrm{L} \mathrm{BAP}$ and $0.25 \mathrm{mg} / \mathrm{L}$ Kinetin (Table 2 and Figure 2(B)) while the same medium composition resulted in only 5.47 and 6.76 shoots per explant in Q200 and Co-0238 genotypes respectively. Similarly, Co-0238 produced maximum of 13.56 shoots per explant with average shoot length of $6.67 \mathrm{~cm}$ and mean number of leaves per shoot of 5.50 on MS medium fortified with $1.5 \mathrm{mg} / \mathrm{L} \mathrm{BAP}+0.5 \mathrm{mg} / \mathrm{L}$ kinetin (Table 2 and Figure $2(\mathrm{C})$ ) while the same medium composition resulted in only 5.26 and 6.74 shoots per explant in Q217 and Q200, respectively. In three genotypes, maintaining Kin at $0.25 \mathrm{mg} / \mathrm{L}$ while increasing BAP levels from 0.5 to $2.0 \mathrm{mg} / \mathrm{L}$, showed a marked increase in the number of shoots per explant from 5.50 to $13.59,5.16$ to 5.4 and 3.57 to 3.80 , average shoot length from $2.93 \mathrm{~cm}$ to $5.80 \mathrm{~cm}, 2.87 \mathrm{~cm}$ to $4.13 \mathrm{~cm}, 2.30 \mathrm{~cm}$ to $3.43 \mathrm{~cm}$ and number of leaves per explant from 3.10 to $6.97,3.63$ to $4.87,3.60$ to 4.47 in Q200, Q217 and Co-0238 genotypes, respectively. Increase of kinetin from 0.25 to $1.0 \mathrm{mg} / \mathrm{L}$ without BAP showed a significant increase in the number of shoots per explant from 6.51 to 7.34 but, decrease the average shoot length from 4.37 to $3.60 \mathrm{~cm}$ and number of leaves per shoot from 5.03 to 4.13 in Q217 genotypes. On the other hand, significant reduction of 
the same parameter with the above genotype was observed in Q200 and Co-0238 varieties.

Regarding shoot length, Q200 produced the highest shoot length $(5.83 \mathrm{~cm})$ with the maximum number of leaves per shoot (6.97) on MS medium supplemented with $2.0 \mathrm{mg} / \mathrm{L}$ BAP alone, whereas only $4.13 \mathrm{~cm}$ and $3.43 \mathrm{~cm}$ shoot length with 4.87 and 4.47 leaves per shoot production in Q217 and Co-0238, respectively. This different shoot length growth response to the similar media composition might be as a result of difference in inherent endogenous growth hormone level among genotypes (George et al., 2008).

It is evident from Table 2 that the use of $2.0 \mathrm{mg} / \mathrm{L}$ BAP alone produced only 5.16 shoots per explant, which was increased to 15.28 shoots by addition of $0.25 \mathrm{mg} / \mathrm{L}$ kinetin in genotype Q217. In similar way, increased shoot number per explant was observed in genotype Co-0238 from 3.80 to 13.56 when $0.5 \mathrm{mg} / \mathrm{L}$ kinetin was added to MS medium containing $1.5 \mathrm{mg} / \mathrm{L}$ BAP. This positive effect implies the significance of adding the two growth regulators in combination rather than alone in shoot multiplication medium. Ali and Afghan (2001) reported that medium supplemented with BAP and Kinetin resulted in rapid multiplication of shoots.

When the same concentration of Kinetin $(0.5 \mathrm{mg} / \mathrm{L})$ and BAP $(0.5 \mathrm{mg} / \mathrm{L})$ are used in combination for shoot multiplication, Q200 genotype produced more number of shoots (6.72) per explant than other genotypes. The same is also true when $1.0 \mathrm{mg} / \mathrm{L}$ Kinetin and $1.0 \mathrm{mg} / \mathrm{L}$ BAP were used in combination. This result also points out that different genotypes show different performance on the same hormone (cytokinins) concentration and combination.

The best result achieved in genotype Co-0238 is consistent with the result obtained by Khan et al. (2009). They reported variety HSF-240 produced 11 shoots per explant; 16.5 cm mean shoot length and 32 leaves per shoot on MS medium fortified with $1.5 \mathrm{mg} / \mathrm{L}$ BAP+ $0.5 \mathrm{mg} / \mathrm{l}$ kinetin. Dereje et al. (2014) reported maximum multiplication from C8612 genotype with $33.8 \pm 0.837$ shoots per explant, $8.4 \pm 0.008 \mathrm{~cm}$ mean shoot length and $13.04 \pm 0.089$ leaves per shoot on MS medium fortified with $1.5 \mathrm{mg} / \mathrm{L} \mathrm{BAP}+0.5 \mathrm{mg} / \mathrm{l}$ kinetin. The present result in Q217 is also in agreement with the results reported by Tilahun et al. (2014) who obtained best result from Co-449 genotype on MS medium 
fortified with $2.0 \mathrm{mg} / \mathrm{L} \mathrm{BAP}+0.25 \mathrm{mg} / \mathrm{L}$ Kinetin with $7.87 \pm 1.06$ number of shoots, $6.33 \pm 0.21 \mathrm{~cm}$ shoot length and $5.44 \pm 0.19$ leaves per shoot. The result in Q200 is similar with the report of Belay (2014) who found optimum result from N14 genotype on MS Medium fortified with $2.0 \mathrm{mg} / \mathrm{L}$ BAP without kinetin with $21 \pm 0.58$ numbers of shoots, $5.63 \pm 0.01 \mathrm{~cm}$ shoot length and $5.4 \pm 00$ leaves per shoot.

In the three cases, the observed difference in number of shoots per explant, number of leaves and shoot length could be due to genotypic difference. Similar results were also reported by Sandeep et al (2008) who observed an average of 19.91 shots on MS medium fortified with $2.0 \mathrm{mg} / \mathrm{L} \mathrm{BAP}$ alone. However, there are also reports (Sawant and Meti, 2016, Yadav et al, 2012) that indicated higher multiplication rate of sugarcane varieties at lower concentration of BAP and kinetin than obtained in this study. Result of the present study indicated that $1.5 \mathrm{mg} / \mathrm{lBAP}+0.50 \mathrm{mg} / \mathrm{l}$ kinetin was the optimum and best hormone concentration and combination for maximum shoot multiplication of sugar cane genotype Co-0238. The present result showed that $2.0 \mathrm{mg} / \mathrm{L} \mathrm{BAP}+0.25 \mathrm{mg} / \mathrm{L}$ kinetin, and $2.0 \mathrm{mg} / \mathrm{L} \mathrm{BAP}$ alone was found to be the best for sugarcane genotype Q217 and Q200, respectively. Comparison of the three genotypes showed that Q217 was a better responsive than Q200 and Co-0238 for in vitro multiplication in full MS medium.

Table 1.Effect of BAP and IBA on establishment of shoots

\begin{tabular}{|c|c|c|c|c|c|c|c|}
\hline \multicolumn{2}{|c|}{ PGR(mg/L) } & \multicolumn{6}{|c|}{ Sugarcane Varieties } \\
\hline \multirow{2}{*}{ IBA } & \multirow[b]{2}{*}{ BAP } & \multicolumn{2}{|c|}{ Q200 } & \multicolumn{2}{|l|}{ Q217 } & \multicolumn{2}{|l|}{ Co-0238 } \\
\hline & & $\begin{array}{l}\text { shoots } \\
\text { established }\end{array}$ & $\%$ of establishment & $\begin{array}{l}\text { shoots } \\
\text { established }\end{array}$ & $\begin{array}{l}\% \text { of } \\
\text { establishment }\end{array}$ & $\begin{array}{l}\text { shoots } \\
\text { established }\end{array}$ & $\begin{array}{l}\% \text { of } \\
\text { establishment }\end{array}$ \\
\hline 0 & 0 & 0 & $0 \%$ & 0 & $0 \%$ & 0 & $0 \%$ \\
\hline 0 & 1.5 & 12 & $40 \%$ & 13 & $43.3 \%$ & 14 & $46.6 \%$ \\
\hline 0 & 2 & 17 & $56.6 \%$ & 15 & $50 \%$ & 11 & $36.6 \%$ \\
\hline 0.5 & 0 & 3 & $10 \%$ & 4 & $13.3 \%$ & 2 & $6.6 \%$ \\
\hline 0.5 & 1.5 & 16 & $53.3 \%$ & 18 & $60 \%$ & 28 & $93.3 \%$ \\
\hline 0.5 & 2 & 26 & $86.6 \%$ & 27 & $90 \%$ & 17 & $56.6 \%$ \\
\hline
\end{tabular}


Table 2.The effect of BAP and Kinetin on number of shoots per explant, shoot length and number of leaves per shoot

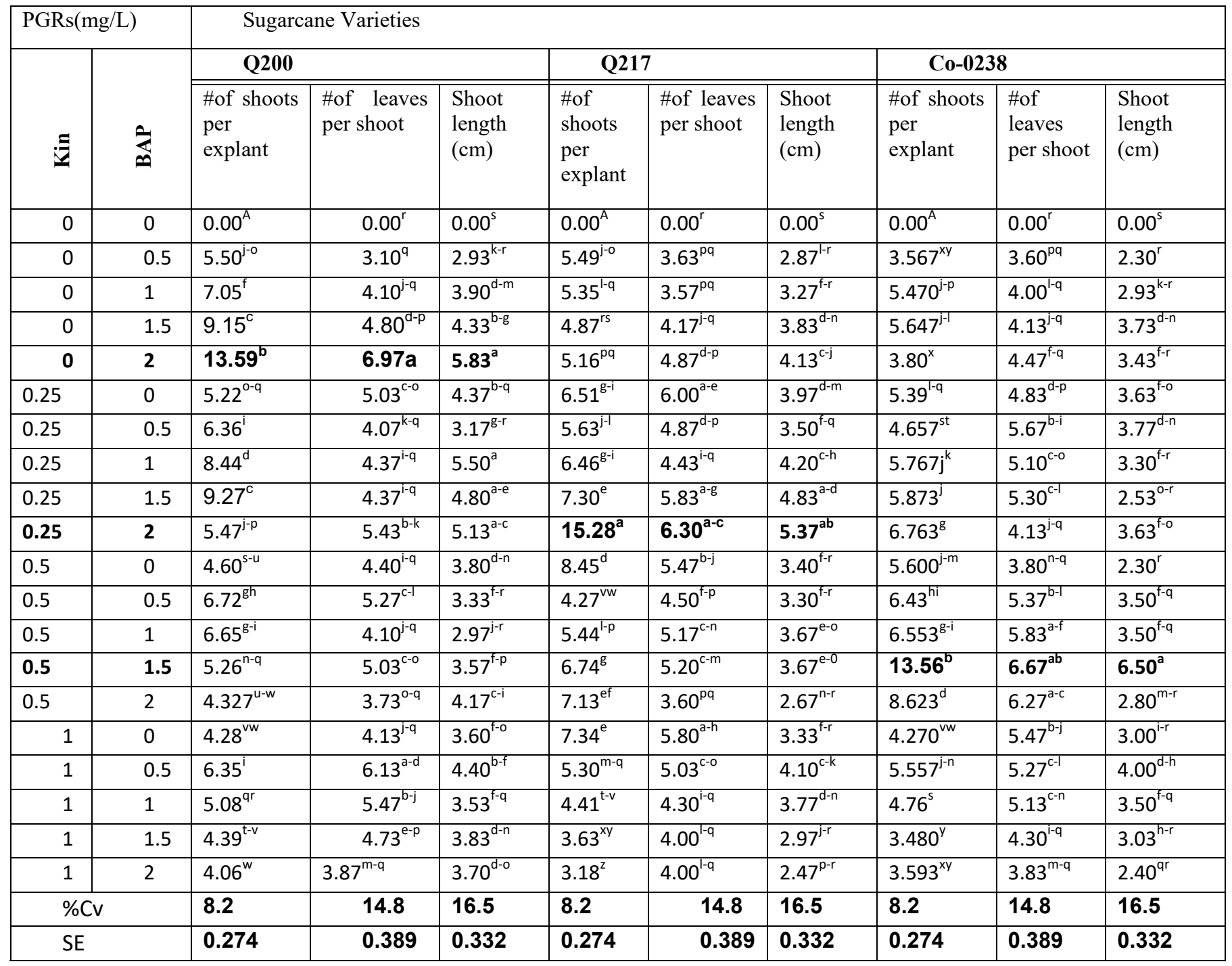



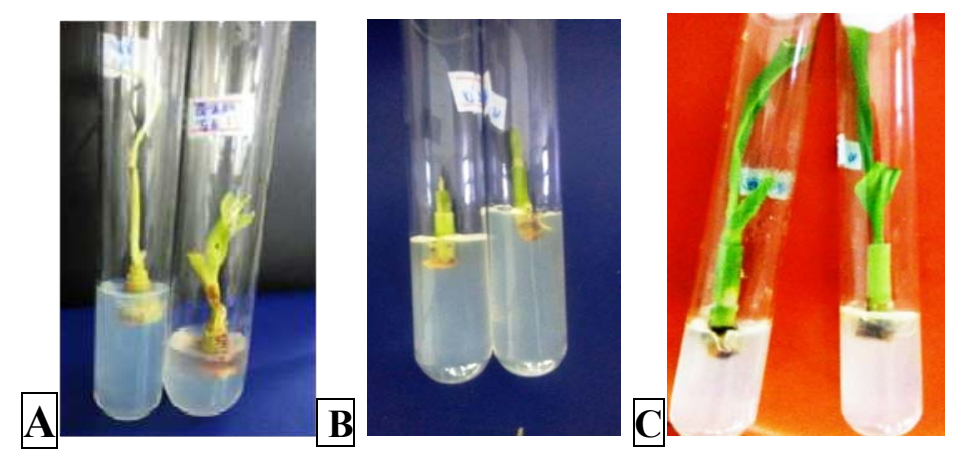

Figure 1.Shoot tip culture initiation and establishment of three genotypes

A. Q200 on MS medium containing $0.5 \mathrm{mg} / \mathrm{L} \mathrm{IBA}+2.0 \mathrm{mg} / \mathrm{LBAP}$

B. Q217 on MS medium containing $0.5 \mathrm{mg} / \mathrm{L} \mathrm{IBA}+2.0 \mathrm{mg} / \mathrm{LBAP}$

C. Co-0238 on MS medium containing $0.5 \mathrm{mg} / \mathrm{lBA}+1.5 \mathrm{mg} / \mathrm{l} \mathrm{BAP}$

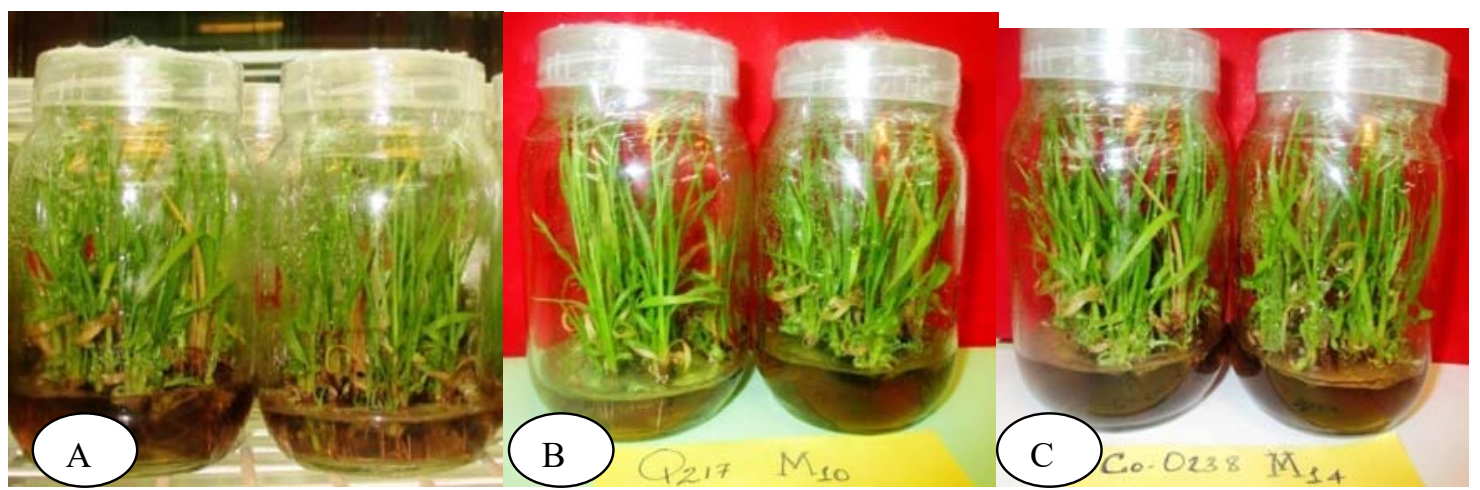

Figure 2.In vitro shoot multiplication of three sugarcane genotypes

A. Q200 on $2.0 \mathrm{mg} / \mathrm{l} \mathrm{BAP}$

B. Q217 on $2.0 \mathrm{mg} / \mathrm{l} \mathrm{BAP}$ and $0.25 \mathrm{mg} / \mathrm{l}$ kinetin

C. $\mathrm{Co}-0238$ on $1.5 \mathrm{mg} / \mathrm{l} \mathrm{BAP}$ and $0.5 \mathrm{mg} / \mathrm{l}$ kinetin.

\section{Conclusions}

From the result obtained in the study, it is concluded that the developed protocol is helpful for rapid in vitro propagation of the sugarcane planting materials and hence enhance the availability of healthy and true to type planting materials in Ethiopian sugarcane plantations

\section{Conflict of Interest Statement}

The authors have no conflicts of interests to declare.

\section{Acknowledgments}

The study was sponsored by Adami Tulu Agricultural Research Center of Oromia Agricultural Research Institute. The authors would like to thank Dr. Tileye Feyissa for his valuable advice, supervision and constant patience through all time during this work and Holeta National Biotechnology Laboratory for providing part of lab facilities. 


\section{References}

1. Baksha.R, Alam. R, K a r i m M.Z., Mannan.S. K., Podder, B.P. and Rahman, A.B.M.M. (2002). Effect of Auxin, Sucrose and pH Level on in vitro rooting of callus Induced micro shoots of Sugarcane (Saccharum officinarum). Journal of Bioloical Science. 3: 915-920.

2. Belay Tolera, Mulugeta Diro and Derbew Belew (2014). Effects of Gibberellic acid and kinetin on In vitro aseptic shoot tip culture establishment of sugarcane (Saccharum Officinarum L.) varieties grown In Ethiopian Sugar Estates. International Journal of Science: Basic and Applied Research 16: 496-504

3. Belay Tolera, Mulugeta Diro and Derbew Belew (2014). Response of Sugarcane (Saccharum officinarum L.) Varieties to BAP and Kinetin on in vitro shoot multiplication. International Journal of Innovative Research and Development 3694697

4. Dereje Shimelis, Kassahun Bantte and Tileye Feyissa (2014). Interaction effects of 6benzylaminopurine and Kinetin on in vitro shoot multiplication of two sugarcane (Saccharum officinarum L.) genotypes. Advanced Crop Science Technology 2:1-5.

5. George, E. F., M. A. Hall, and G.J. De. Klerk, (2008). The components of plant tissue culture media I: macro-and micro-nutrients Springer. Netherlands. 65-113

6. Hoy J.W., Bischoff K. P., Milligan S. B. and Gravois K. A. (2003). Effect of tissue culture explant source on sugarcane yield components. Euphytica 129: 237-240

7. Jai Godhejaa, Sudhir K., Shekharb, and D.R. Modi (2014). The standardization of protocol for large scale production of sugarcane (co-86032) through micro propagation. International Journal of Plant, Animal and Environmental Science 4:135143

8. Khan SA, Rashid A, Chaudhary MF, Chaudhary Z and Afroz A (2008) Rapid Micro propagation of three elite Sugarcane (Saccharum officinarum L.) varieties by shoot tip culture. African Journal of Biotechnology 7:2174-2180.

9. Melaku T., Belayneh A., and Kassahun B. (2016). In Vitro Shoot Multiplication of Elite Sugarcane (Saccharum officinarum L.) Genotypes Using Liquid Shake Culture System

10. Pathak S, Lal M, Tiwari .A.K, and Sharma M.L (2009). Effect of growth regulators on invitro multiplication and rooting of shoot cultures in sugarcane. Sugar Technology 11: 86-88.

11. R. A. Sawant and N.T. Meti (2016). Cost effective techniques for invitro propagation of two varieties of sugarcane. International Journal Current Research in Bioscience and Plant Biology 3: 65-72

12. Sandeep Biradar D. P., Biradar V. C., Patil S. S., Patil and N. S. Kambar (2008). In vitro plant regeneration using shoot tip culture in commercial cultivar of sugarcane. Karnataka Journal Agricultural Science 22:21-24

13. Singh N, Kumar A. and Garg G.K. (2006). Genotype influence of Phytohormones combination and sub culturing on Micropropagation of sugarcane varieties. Indian Journal of biotechnology 5: 99-106. 
14. Tilahun M.,Mulugeta D., Manju Sh., and Tadese N.(2014). Protocol optimization for invitro mass propagation of two sugarcane (Saccharum officinarum) clones grown in Ethiopia 13:1358-1368

15. Yadav S., A. Ahmad and Lal, (2012). Effect of different Auxins and cytokinins on in vitro multiplication and rooting of shoot cultures in sugarcane. International Journal of Biological \& Pharmaceutical Research 3:814-821. 